$\xi=$ 不

\title{
Peat stratigraphy mapping using ground penetration radar and geotechnical engineering implications
}

\author{
Godfrey T. Akpabio ${ }^{1 *}$, Ubong A. Johnson ${ }^{1}$, Calrlos Vargas Cana ${ }^{2}$, Okechukwu E. Agbasi ${ }^{1}$ \\ ${ }^{1}$ Department of Physics, Faculty of Science, University of Uyo \\ ${ }^{2}$ Weather Reservoir Solutions, Colombia \\ *Corresponding author E-mail: ebukasean09@yahoo.com
}

\begin{abstract}
A Combined Land and Marine Ground Penetrating Radar (GPR) surveys was carried out in Southwestern part of Lagos, Badia, Nigeria with a view of delineating the subsurface peat stratigraphy that would aid geotechnical engineering design of the appropriate soil stability processes. The GPR study was conducted along eight parallel traverses trending East-West, using the Geophysical survey system incorporated (GSSI) SIR-3000 200MHZ Monostatic shielded antenna. Geographically, the study area is approximately between latitude $715000 \mathrm{~N}$ and $716000 \mathrm{~N}$ and longitude $538600 \mathrm{E}$ and $540300 \mathrm{E}$ of the universal traverse Mercator. The antenna was present with three gain points in order to improve the scans during data acquisition while 33 scans per meter were taken (representing $3 \mathrm{~cm}$ station spacing) with a sampling window of $400 \mathrm{~ns}$ with offset of $+25 \mathrm{~ns}$. The topography is generally flat with localized undulations due to sand heaps from canals dredging and sand filling activities in the area. The peat depth was found to vary from $1.5 \mathrm{~m}$ to $6 \mathrm{~m}$ and the thicknesses from traverse one (1) to eight (8) on chainage $625 \mathrm{~m}$ to $1100 \mathrm{~m}$. The area belongs to Dahomey Basin which is also known as Dahomey Embayment or Benin Benin or as West Nigeria Basin. The mineralogy, micro-fabrics and Morphology of the delineated stratigraphy was determined using the Scanning Electron Microscope (SEM) and X-Ray diffraction (XRD) methods. The results obtained revealed the presence of five subsurface (Topsoil/ sand filled Layer, Silty Clay, Peat, sandy Clay and Silty Sand) geological Layers, distinct geomorphological features, and high, moderate and low amplitudes, to continuous and discontinuous planer relax Facies structures. SEM and XRD analyses of the field samples obtained showed the dominance of Kaolinite, illite and quarts minerals in the clay/peat mapped. The derived engineering parameters suggest that the peat found in the study area are "fibrous peat" with low strength and medium to low bedding stress. It is observed that the peat generally depict high compressibility value, low internal frictional angle, they exhibit low elastic properties such as low shear modulus, low bulk modulus and young modulus values. The findings confirm the efficacy and relevance of GPR technique for pre-construction engineering investigation.
\end{abstract}

Keywords: Ground Penetrating Radar; Stratigraphy; Geotechnical Engineering; Lagos.

\section{Introduction}

In broad terms, the subsurface exploration and soil investigations are important part of civil and/or geotechnical engineering, where most of the designs are based on the results obtained from these methods. In-situ testing are practiced to determine the properties of subsurface materials using conventional methods of boring, standard penetration tests and cone penetration test that provide information at a particular point, but spatial variation of geotechnical material and rock depth are essential for effective design of foundation and basement floors. In modern practice, GPR method is routinely used for effectively, map the spatial variation of soil and rock layers with its thickness. GPR is a non-destructive method that produces a continuous cross-sectional profile or record of the desire subsurface features, without drilling, probing or digging. It is an environmentally friendly and safe method to detect, locate and map subsurface features.

This provides information on the subsurface lithology delineated using the GPR methods, the thicknesses of the lithology and the engineering characteristics estimated using empirical relations. Peat soil are generally defined as unconsolidated organic material consisting largely of organic residues accumulated as result of incomplete decomposition of dead plants constituents under con- ditions of excessive moisture (Landva, 2007) . It is generally accepted that the organic matter present in peat soils causes a detriment to their geotechnical and engineering qualities (Malkanci et al, 1999). Engineers worldwide consider peat soils as problematic soil because of their perceived abnormal geotechnical properties. These soils according to Kazemian et al (2011) are geotechnical problematic and cause instability problems such as development of slip failure, local sinking and massive primary and long term settlement even when load increases moderately. Therefore peaty soils as they are weak and highly compressible (Duraisawy et al. 2007). The depth of the peat varies between 31 and 35 percent, the engineering properties such as velocity, Young modulus, shear Modulus and bulk Modulus of the samples were within the range as reported by Haut (2004) for peat found in the tropical region. Lagos metropolis lies within the Benin basin which constitutes a part of the post Hercynian merging sag basins of West African developed a brief period of rifting in the early cretaceous to Late Jurassic associated with the Benue Trough Complex and the development of the Atlantic Ocean. This was followed by the extended period of thermally induced basin subsidence through the middle-upper cretaceous to tertiary times as the South American and African Plates entered a drift phase surface soils and many underlying formations may contain significant amount of solid matter derived from organisms. While shell fragments and similar 
solid matter are found at some locations, organic materials in soil is usually derived from plant or root growth and consists almost completely disintegrated matters, such as muck or more fibrous material, such as peat.

However, of all the soils suitable for foundation support, the presence of organic materials make peat and organic soils in general, difficult foundation materials because they exhibit very high compressibility compared with inorganic soils such as sands and gravel, (Cola and Cortellazzor, 2004). The behavior of a soil mass under load depends upon many factors such as the properties of the various constituents present in the mass, the degree of intensity, the degree of saturation, the environmental conditions, etc. The in opposite property of peats to engineering works has led to various invasive investigation to determine their compressibility and engineering properties in order to evaluate foundation settlements. The density values obtained are uniquely uniform with varying depth of $1.5 \mathrm{~m}$ to $18 \mathrm{~m}$, chang et al. 2006 showed that along with the unconfined compressive strength of rocks and sorts, the angle of internal friction is another strength parameter necessary to estimate rock strength at depth. From this study, the predicted internal friction angle increases monotonically from three degree to ten degree, as P-waves velocity increases from $1.83 \mathrm{~km} / \mathrm{s}$ to $1.87 \mathrm{~km} / \mathrm{s}$ and as $\mathrm{S}$-wave velocity increases from $0.883 \mathrm{~km} / \mathrm{s}$ to $0.89 \mathrm{~km} / \mathrm{s}$.

The derived internal friction angle indicates that the peat investigated is possibly heterogeneous in nature. Also, the derived engineering parameters for this study suggest that the peat found in the investigated areas are fibrous peat with low shear strength, medium to low bedding stress and high water volume content. The engineering implications of these derived values imply that for any engineering structures to be constructed at any of this location, proper and adequate soil stabilization and improvement processes such as chemical injection (Wet Mixing), deep mixing (Cortellazzo and Cola, 1999, Nebib and Farrell, 1999) must be embarked upon in order to strengthen the sedimentary soil. If the construction exercise is carried out without applying any of the suggested ground improvement techniques, the likelihood of the soil undergoing differential settlement and ground subsidence is very high in the area.

GPR is a high resolution geophysical method which is based on the propagation of high frequency electromagnetic waves, this method images structure in the ground that are related to changes in dielectric properties and in determining stratigraphic architecture, correlation and quantification of sedimentary structures. Ground subsidence and settlement have posed great challenges to engineering structures, in some cases, resulting in moderate to severe damage. The high rate of buildings and infrastructural failures in Nigeria especially Lagos area, Badia in particular which always involve loss of lives and properties in recent times, calls for diverse subsurface investigation that could aid in engineering design to fore stall such failures. (Adepelumi and Fayemi, 2013).

Hence, necessitating site characterization using geotechnical and geophysical methods for structural engineering purpose before further constructions are carried out in these areas.

\section{Location of the study area}

The study area is in the southern fringe of Lagos in Nigeria, specifically in Badia community. It is one of the six communities in Apapa Local Government Area of Lagos State. Geographically, it is bounded by latitude $7^{\prime} 15^{\prime}, 00^{\circ} \mathrm{N}$ and $7^{\prime} 16^{\prime}, 00^{\circ} \mathrm{N}$, and longitude $5^{\prime} 38^{\prime}, 60^{\circ} \mathrm{E}$ and $5^{\prime} 40^{\prime}{ }^{\prime} 30^{\circ} \mathrm{E}$, and spans about 55.07 hectares. It is bounded in the east by railway line that runs parallel with Apapa Road. To the North of the study area is Lagos -Badagry expressway. To the South is Gasikiya College Road and to the West is the other part of Badia which extends to Ojo.

The investigated site at Badia Lagos is in Southwestern Nigeria which is part of the Dahomey basin. Sedimentation in this basin dates back to early cretaceous after the separations of African South America landmasses and subsequent opening of the Atlantic Ocean (Adegoke and Omatsola 1981).

The oldest sedimentary unit on shore within the basin is the Cretaceous grits and sandstones of Abeokuta group. These strata are overlain on shore by the marine Paleocene limestone and shale of the Ewekoro formation. Overlying the Paleocene strata are the sand and clays of Ilaro formation. These lower Tertiary beds are overlain by the Coastal Plain sand composed of transitional to continental sands of Oligocene to Recent age (Figure 1).

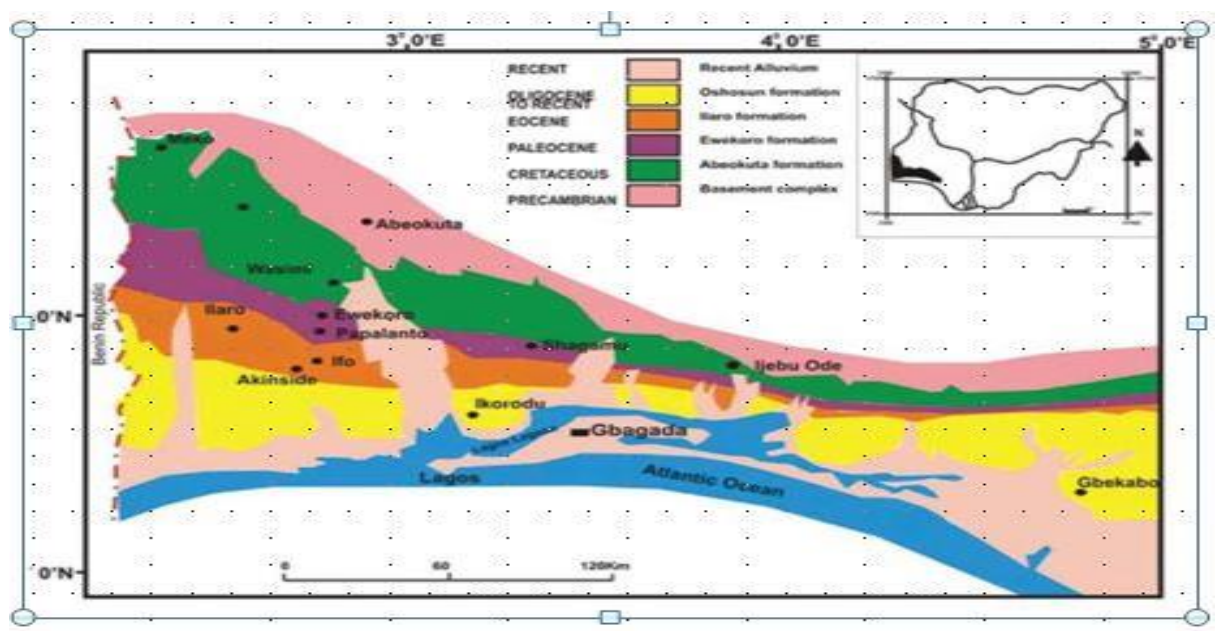

Fig. 1: Regional Geology of Dahomey Basin Showing Lagos State and Environs (Durotoye, 1975).

The surface local geology of the study area is consistent with the regional geological setting of Lagos area as described by Longe, et al., (1987). The surface geology of the study area is made up of the Ilaro Formation and the recent littoral alluvial to Coastal Plain sand deposits (Benin Formation). The local subsurface geology is made up of the Benin formation (Miocene to Recent) and the recent littoral alluvial deposits (Jones and Hockey, 1964).The Benin formation consists of thick bodies of yellowish (ferruginous) and white sand. It is friable, poorly sorted with intercalation of shale, clay lenses and sandy clay with lignite. The Ilaro Formation consists of rather massive sandstone with local clay intercalations.
The Ilaro Formation is fine to medium grained, and is fairly well sorted. The Ilaro Formation lies conformably on the Oshosun Formation (Lower - Middle Eocene) and locally unconformably beneath the Benin Formation (Oligocene-Pleistocene). The Ilaro Formation is estimated to be about $70 \mathrm{~m}$ thick and shows rapid lateral facies changes. The Ilaro Formation is mostly likely to be Middle to Upper Eocene in age.

The Benin Formation consists of continental sands with shale intercalations usually with good groundwater potential. This can affect the aquifer quality of the Ilaro Formation (Durotoye, 1975). However, the underlying Ewekoro Formation is known to have 
good groundwater aquifer (limestone). The investigated area contains good aquifers that are harnessed through hand-dug wells with very shallow depth extent. The recent littoral and alluvium deposits, the continental Benin sands and the Ilaro Formation were identified as the major aquifers from various geological and geophysical works. The groundwater level varies between $1 \mathrm{~m}$ and $2 \mathrm{~m}$. The water-bearing aquifers consist of sands, gravels or a mixture of the two. Textural variations from fine through medium to coarse sands and gravels occur and they are poorly to well sorted. When near the surface, the sand deposits are generally loose but become moderately dense with depth and occasionally with clay interbeds (Longe et al, 1987). The area is well suited for water supply through boreholes.

The first aquifer horizon identified by Longe et al. (1987) occurs between 2 and $26 \mathrm{~m}$ below sea-level and is made up of yellow to light grey coarse sands and gravels. It is underlain by a continuous swampy materials comprising of fibrous peat and impermeable organic matter. The organic layer confines the second aquifer and has a thickness of $12-36 \mathrm{~m}$.

The second aquifer horizon occurs between 38 and $109 \mathrm{~m}$ below sea-level. The continuity of the aquifer is broken by dark grey and soft clay and peat lenses. The water bearing horizon consists of poor to fairly well sorted unconsolidated medium to coarse grained grayish sands. The horizon is underlain by a continuous clay layer of variable thickness that separates it from the third aquifer. This second aquifer horizon has an average transmissivity, storage coefficient and leakage coefficient of $3.5 \times 10^{-3} \mathrm{~m}^{2} \mathrm{~s}^{-1}$, $2.9 \times 10^{-4}$ and $3.2 \times 10^{-9} \mathrm{~s}^{-1}$ respectively. The leakage factor suggests drainage from this aquifer horizon to the one below. The aquifer belongs to the Ilaro Formation.

The third aquifer horizon occurs between 120 and $270 \mathrm{~m}$ below sea level and is characterized by alternating sequences of clay and gravelly sands.

The investigated area at Badia is located at Apapa/Iganmu Local Council Development Area of Lagos. The area lies within the coastal Plateau Geomorphic unit (Adegoke et al, 1980). Adegoke et al 1980 recognized the following fire geomorphologic sub-units within the coastal region of Western Nigeria:

\section{Abandoned beach ridge complex}

1) The coastal Greeks and Lagoons

2) The swamp flats

3) The forested river floodplain

4) The active barrier beach complex

The Badia area is within the abandoned beach ridges complex. The area is low lying and elevation ranges from $0.5 \mathrm{~m}$ to about $3.0 \mathrm{~m}$ above mean seas-level.

The area lies within the rain forest zone of Nigeria with mean Annal rainfall of above $150 \mathrm{~mm}$. The climate of the area has two regimes of wet and dry season controlled by the dry north easterly air mass of Sahara Origin and the humid maritime air mass blowing from over the Atlantic, both blowing from nearly opposite directions. The surface water network drains into the lagoon and Atlantic Ocean Southwards. The vegetation of the area is classified into the freshwater swamp and high forest. Coastal Greeks and lagoons constitute the fresh swamp (Iloeje, 1976). Physically, the entire areas is swampy with sand filling in isolated areas for construction of dwellings. The area is not drained, during dry season, water level is about $300 \mathrm{~mm}$ below ground level in up to $70 \%$ of the entire study area while some are below sea level (Apapa Local Government, 2002). During wet season, the whole area is submerged in flood for more than three hours after each rain with some areas remaining totally submerged throughout the entire wet season.

\section{Materials and method}

\subsection{Ground penetrating radar method}

Ground-penetrating radar (GPR, also referred to as groundprobing radar, surface-penetrating radar, subsurface radar, georadar or impulse radar) is a non-invasive geophysical technique that detects electrical discontinuities in the shallow subsurface (usually less than $50 \mathrm{~m}$ ). It does this by generation, transmission, propagation, reflection and reception of discrete pulses of high frequency $(\mathrm{MHz})$ electromagnetic energy which interact with subsurface features at shallow depth (Neal, 2004). GPR uses electromagnetic fields (EM) to probe lossy dielectric materials to detect structures and changes in material properties within the materials (Davis and Annan, 1989). Reflection and transmission measurements are employed. With GPR, the electromagnetic fields propagate as essentially non-dispersive waves. The signal emitted through the material is scattered and/or reflected by changes in impedance, giving rise to events which appear similar to the emitted signal. Signal recognition is simple because the return signal "looks like" the emitted signal, much as in seismic reflection (Annan, 2002). GPR systems operate over a finite range of frequency referred to as GPR plateau, where the velocity and attenuation are almost frequency independent. The GPR plateau usually occurs in the 1 $\mathrm{MHz}$ to $1000 \mathrm{MHz}$ frequency range. At lower frequencies, the fields become diffusive in character and pulses are dispersed. At higher frequencies, several factors increase signal absorption such that penetration is usually extremely limited (Annan, 2002). Radar systems can be deployed in three basic modes which are referred to as reflection, common mid-point velocity sounding and transillumination (Annan, 2002).

\subsection{Hydrographic survey}

There are various methodologies in use to carry out a hydrographic survey, depending on the end use of the survey and the size of the area to be surveyed. Vertical depth measurements may be carried out using:

Hand-held calibrated lead sounding line;

Engineering echo sounder recording on paper; and

Advanced engineering echosounder recording on a data logger and linked to position fixer via integrated software (fully automated), and the

The horizontal position fixing technique. However, for this work, the horizontal position fixing technique was adopted because of the ground logistics and security issues.

\subsection{GPR data acquisition}

For this study, GPR data was acquired along eight (8) parallel traverses approximately East-West, using the Geophysical Survey System Incorporated SIR system-3000 equipment (See Appendix A for the field photographs). The survey was done using a $200 \mathrm{MHz}$ monostatic shielded antenna oriented parallel to the survey direction (parallel-broadside) in continuous collection mode. The antenna was preset with three gain points in order to improve the scans during data acquisition while thirty-three (33) scans per meter were taken (representing $3 \mathrm{~cm}$ station spacing) with a sampling window of $400 \mathrm{~ns}$ with offset of $+25 \mathrm{~ns}$. A 16 -fold stack was used for the traces during data recording to improve the signal to noise $(\mathrm{s} / \mathrm{n})$ ratio of the data. The GPR data positioning was calibrated using a survey wheel (odometer) and each radar trace contains 1024 points per trace. GPR data were acquired both on land and water. The SIR-system and antenna were pulled manually on land during data collection while they were mounted on a wooden boat during data collection on water. All traverses were $530 \mathrm{~m}$ long and ran from land (marshy) to water, with traverse-traverse separation of $2.5 \mathrm{~m}$ (Figure 2). 


\subsection{GPR data processing}

Two kinds of processing; basic and advanced processing were applied to the acquired GPR data.

The basic processing structure include; Data editing (which involve data reorganization, data file merging, data header background information updates, and inclusion of topography information in every file). Zero- offset correction, dew owing, bandpass filtering (with a center frequency of $200 \mathrm{MHZ}$ and Cutoff frequencies of $100 \mathrm{MHZ}$ and $300 \mathrm{MHZ}$ ). Filtering in wave number domain and application of gain functions.

Two gain functions were applied to the data; Automatic gain functions and custom gains. Automatic gains (AGC) increased the amplitude of the signal by a factor inversely proportional to the signal strength. AGC is more effective for recognizing low amplitude reflections (Neal, 2004). The custom gain provided a constant amplitude increase for the signals irrespective of the signal strength loss.

Advanced processing steps that were applied to the radar images include; predictive deconvolution, velocity spectrum analysis, attribute analysis. The intended effect of the deconvolution process was to remove the ringing multiples associated with water layers. The attribute analyses were generated by Hilbert transformation functions, which include instantaneous frequency, instantaneous phase and instantaneous amplitude. A velocity value of $0.13 \mathrm{mn} 5-^{1}$ was obtained from the velocity spectrum analysis of the GPR sections and it was used for the time-depth conversion of the data.

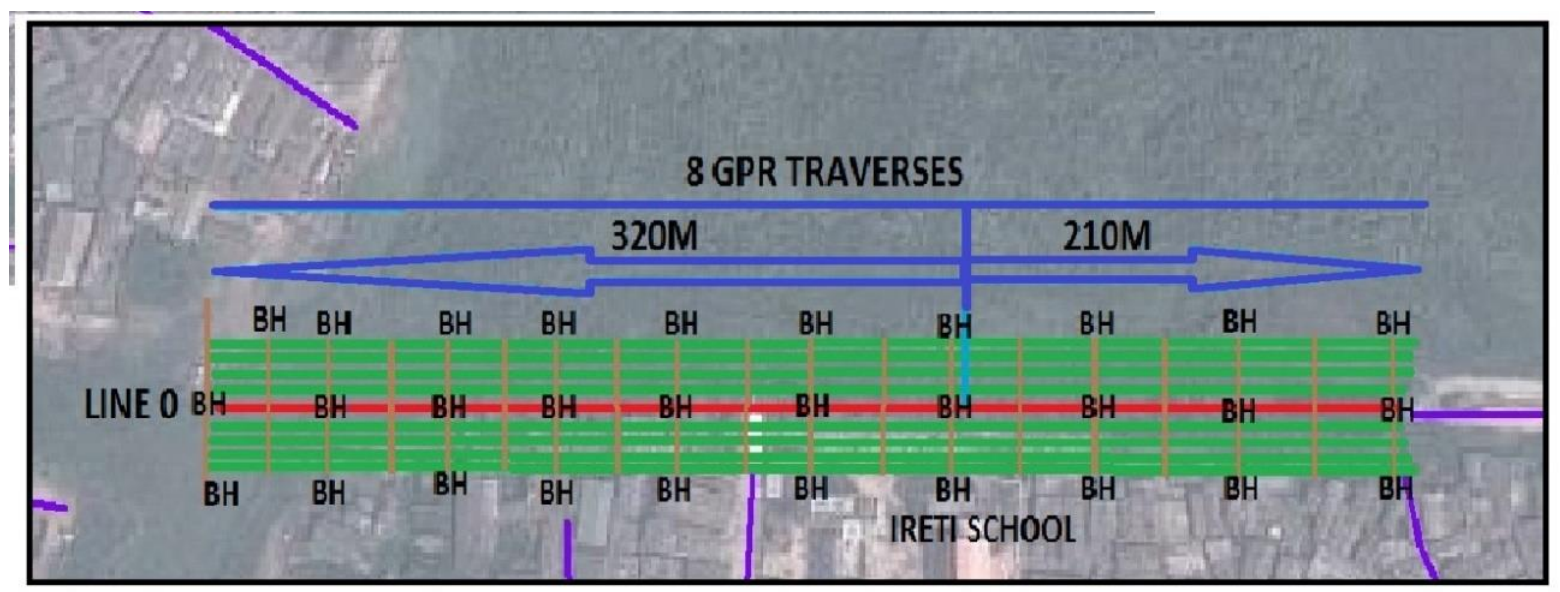

Fig. 2: Google Earth Image of the Study Area Showing the GPR Traverses and the Borehole Locations.

\section{Results and discussions}

The depth of penetration of the radar signals range from $22 \mathrm{~m}$ to $24 \mathrm{~m}$ in the studied area. The results obtained from the processed GPR data are interpreted stratigraphically in terms of the radar facies, in correlation with the borehole logs obtained in the area and with empirical equations to infer the in-situ engineering characteristics of the peat bog.

\subsection{Stratigraphic interpretation}

The stratigraphic interpretation of the GPR sections is done in terms of radar facies for all the traverses. The radar facies observed defines the vertical profile as well as the architectural element - scale features described and interpreted in the borehole logs. The facies are defined using the basic principle of seismic interpretation techniques on the basis of reflection amplitude, continuity and configuration (Mitchum et al., 1977). Five radar facies were recognized from the GPR sections. These are named: F1, F2, F3, F4, F5 and described below;

1) High Amplitude Planar Reflections: This is highlighted in all the sections as F1. It is characterized by high amplitude, planar/even, parallel to sub parallel, horizontal reflection with good continuity. It is interpreted as the top soil/sandfilled area. Its thickness ranges between $0 \mathrm{~m}$ and $1.5 \mathrm{~m}$ and varies (the thickness is not constant even within the same radar profile).

2) Moderate Amplitude Discontinuous Reflections: This is highlighted as F2 in all the sections. It is characterized by moderate amplitude, parallel sinuous/wavy reflections. Its thickness ranges between $9 \mathrm{~m}$ and $14 \mathrm{~m}$ and varies (the thickness is not constant even within the same radar profile). It is interpreted as silty-clay.

3) Low Amplitude Continuous Reflections: This is highlighted as F3 in all the sections. It is the most prominent feature/unit sought after in the study area. It is characterized by low amplitude, parallel sinuous/wavy reflections, often mottled up in places. Its thickness ranges between $2 \mathrm{~m}$ and 5 $\mathrm{m}$ and varies (the thickness is not constant even within the same radar profile). It is interpreted as peat.

4) Moderate amplitude Reflections: This is highlighted as F4 and F5 in all the sections. It is characterized by sub-parallel sinuous (at the upper portion) and wavy (toward the bottom of the radar) reflections, moderately amplitude reflections. This radar facies is interpreted as layer of sandy clay (F4) and silty-sand (F5). 


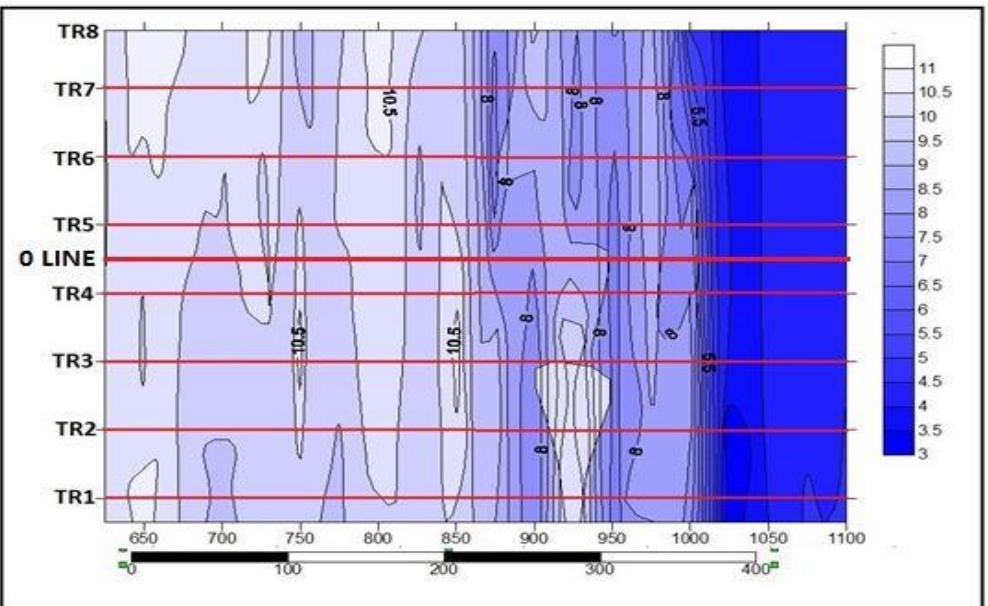

Fig. 3: The Contoured Map of the Peat Thicknesses (Metres) Using the Eight Traverses Commencing at Ch.625m to Ch.1100m.

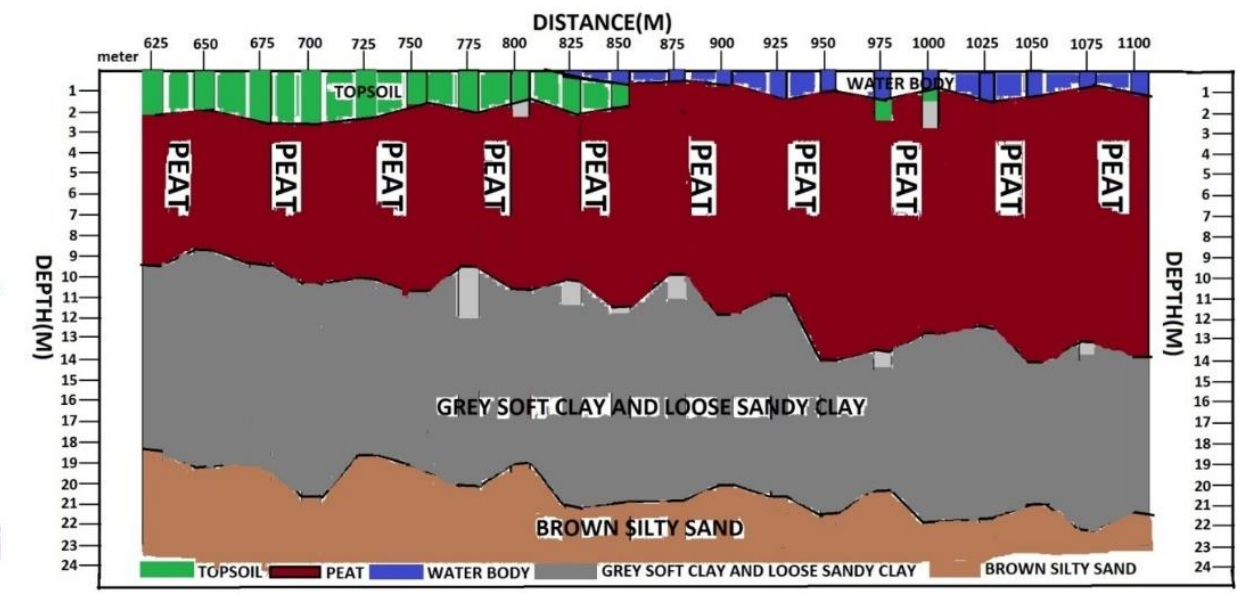

Fig. 4: Stratigraphic Cross Section from Ch.625m- Ch. 1100 (LINE 0).

Table 1: Description of Radar Facies Obtained from the GPR Sections

\begin{tabular}{lll}
\hline Facies & Lithology & Radar Characteristics \\
\hline F1 & Top soil/sand-filled layer & High amplitude planar reflections \\
F2 & Silty clay & Moderate amplitude discontinuous reflections \\
F3 & Peat (with intercalations of clay) & Low amplitude continuous reflections \\
F4 & Sandy clay & Moderate amplitude reflections \\
F5 & Silty sand & Moderate to high amplitude reflections \\
\hline
\end{tabular}

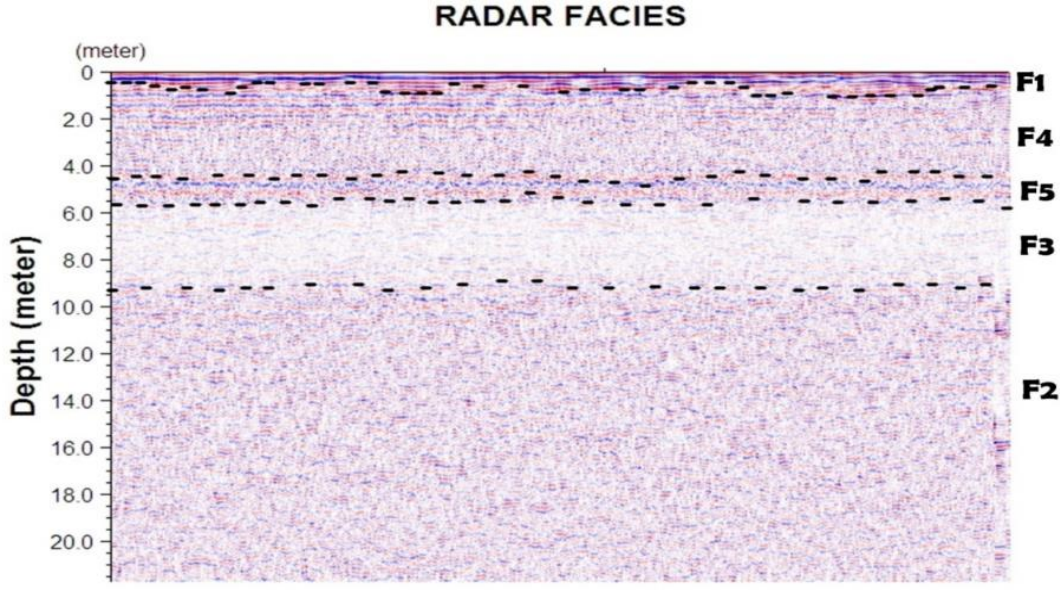

Fig. 5: Radar Facies Identified in GPR Sections.

Traverse 2: The radar facies that characterize the traverse are F4, F5, F3 and F2 (Figure 6). The depth to the water table on is $0 \mathrm{~m}$. The depth of the peat layer ranges from $6 \mathrm{~m}$ to $6.5 \mathrm{~m}$ and the thickness of the peat range from $3.5 \mathrm{~m}$ to $4 \mathrm{~m}$. The lithologic units that occur on the traverse are silty sand, sandy clay, peat and silty clay.

Traverse 3: The radar facies that characterize the traverse are F5, F4, F3 and F2 (Figure 7). The depth to the water table on is $0 \mathrm{~m}$
The depth of the peat layer ranges from $6 \mathrm{~m}$ to $6.5 \mathrm{~m}$ and the thickness of the peat ranges from $3 \mathrm{~m}$ to $3.5 \mathrm{~m}$. The lithologic units that occur on the traverse are silty sand, sandy clay, peat and silty clay.

Traverse 4: The radar facies that characterize the traverse are F1, F3, F4 and F5 (Figure 8). The depth to the water table on is $0 \mathrm{~m}$. The depth of the peat layer ranges from $2 \mathrm{~m}$ to $3 \mathrm{~m}$ and the thickness of the peat range from $10 \mathrm{~m}$ to $11 \mathrm{~m}$. clay intercalations occur 
within the peat layer. The lithologic units that occur on the traverse are topsoil, peat, sandy clay and silty sand.

Traverse 5: The radar facies that characterize the traverse are F1, F4, F3, F5 and F2 (Figure 9). The depth to the water table on is 1 $\mathrm{m}$. The depth of the peat layer ranges from $6 \mathrm{~m}$ to $6.5 \mathrm{~m}$ and the thickness of the peat ranges from $3 \mathrm{~m}$ to $3.5 \mathrm{~m}$. The lithologic units that occur on the traverse are topsoil, sandy clay, peat, silty sand and silty clay.

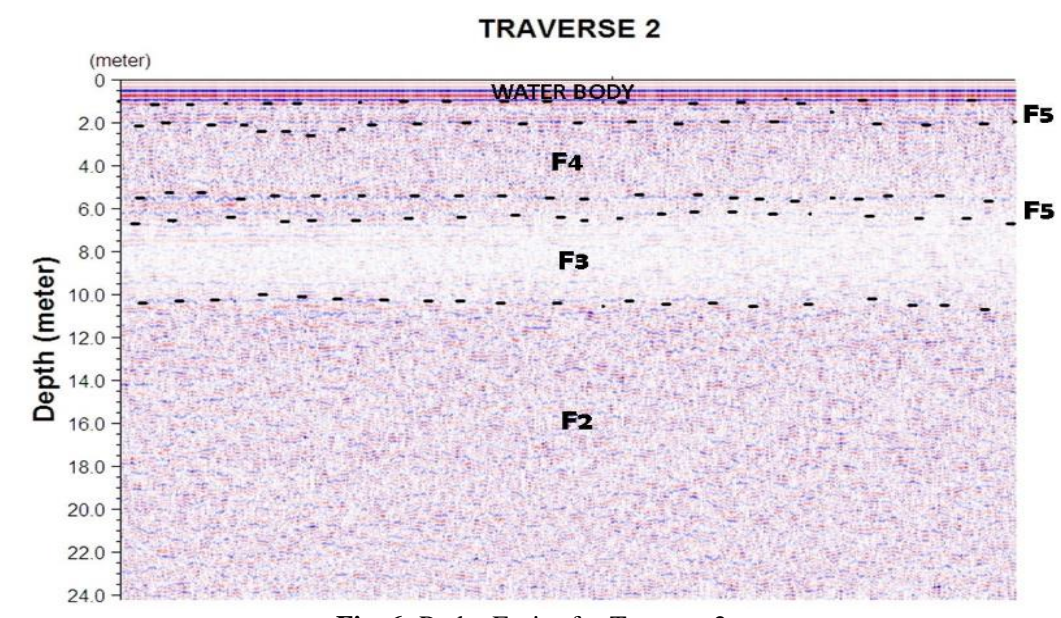

Fig. 6: Radar Facies for Traverse 2.

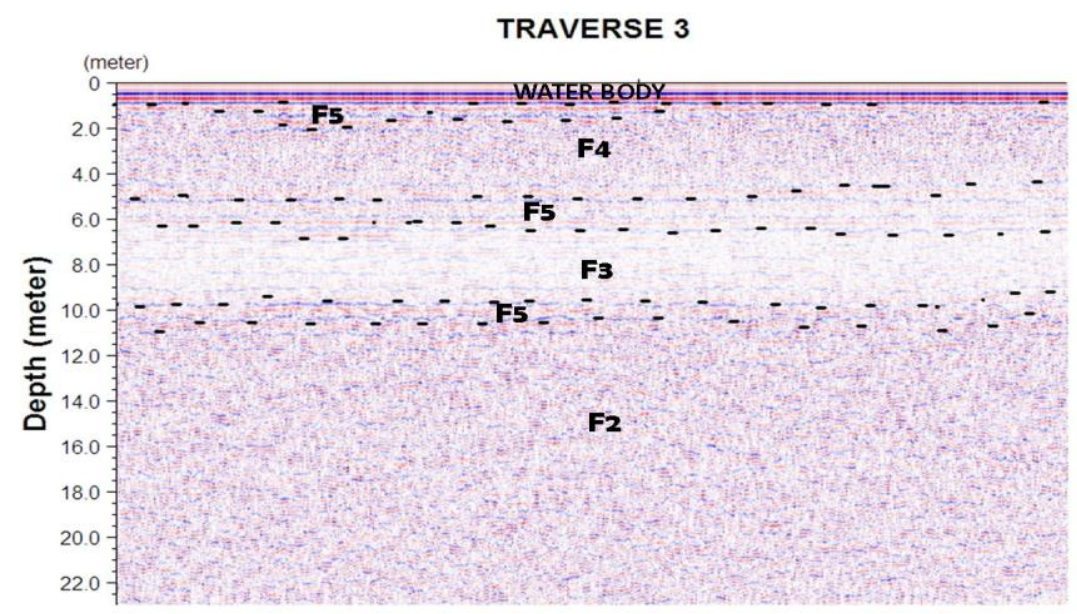

Fig. 7: Radar Facies for Traverse 3.

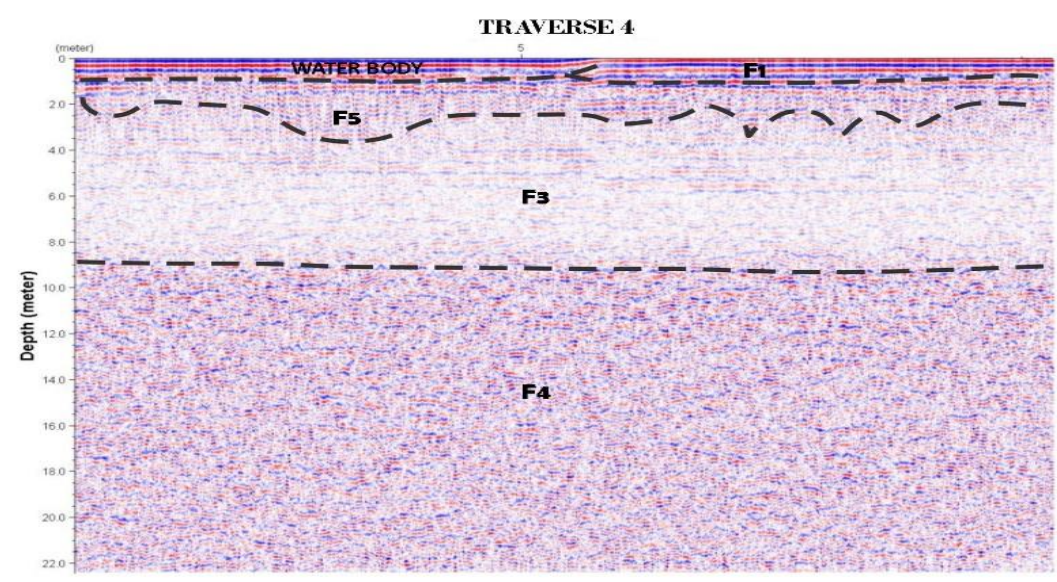

Fig. 8: Radar Facies for Traverse 4.

Traverse 6: The radar facies that characterize the traverse are F1, F5, F3, F4 and F2 (Figure 4.10). The depth to the water table on is $1 \mathrm{~m}$. The depth of the peat layer ranges from $4 \mathrm{~m}$ to $5 \mathrm{~m}$ and the thickness of the peat range from $4 \mathrm{~m}$ to $5 \mathrm{~m}$. The lithologic units that occur on the traverse are topsoil, silty sand, peat, sandy clay and silty clay. A borehole (BH 02 ) was drilled along the traverse and the result of the log interpretation is presented in Figure 4.8.

Traverse 7: The radar facies that characterize the traverse are F1, F5, F3, and F2 (Figures 11). The depth to the water table on is 1 $\mathrm{m}$. The depth of the peat layer ranges from $6 \mathrm{~m}$ to $6.5 \mathrm{~m}$ and the thickness of the peat range from $3 \mathrm{~m}$ to $3.5 \mathrm{~m}$. The lithologic units that occur on the traverse are topsoil, sandy clay, peat, and silty clay.

Traverse 8: The radar facies that characterize the traverse are F5, F3, F4 and F2 (Figure 12). The depth to the water table on is $0 \mathrm{~m}$. The depth of the peat layer ranges from $1 \mathrm{~m}$ to $2 \mathrm{~m}$ and the thickness of the peat range from $3 \mathrm{~m}$ to $4 \mathrm{~m}$. The lithologic units that occur on the traverse are silty sand, peat, sandy clay and silty clay. A borehole ( $\mathrm{BH} \mathrm{06)}$ was drilled along the traverse and the result of the log interpretation is presented in Figure 11. 


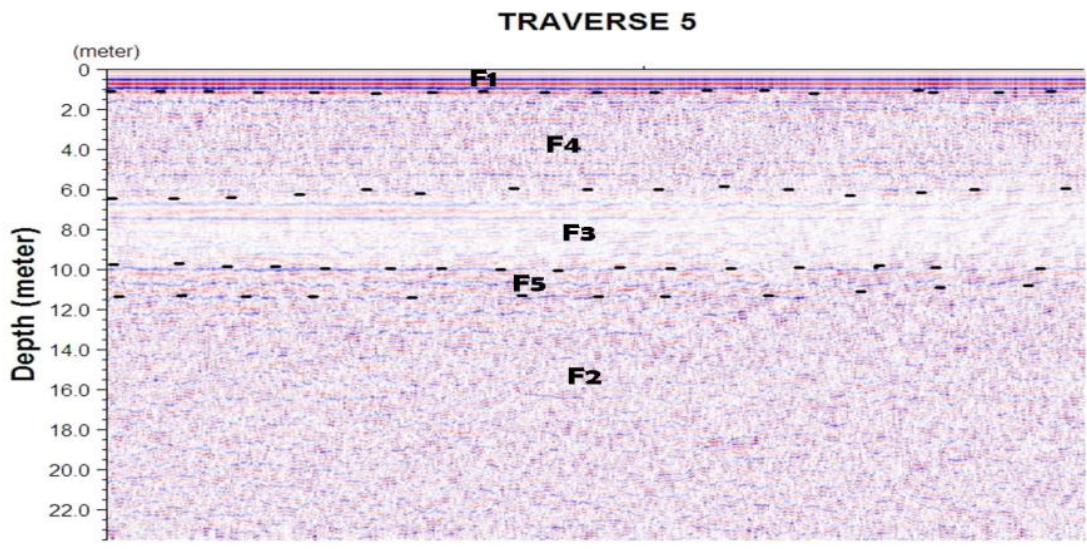

Fig. 9: Radar Facies for Traverse 5.

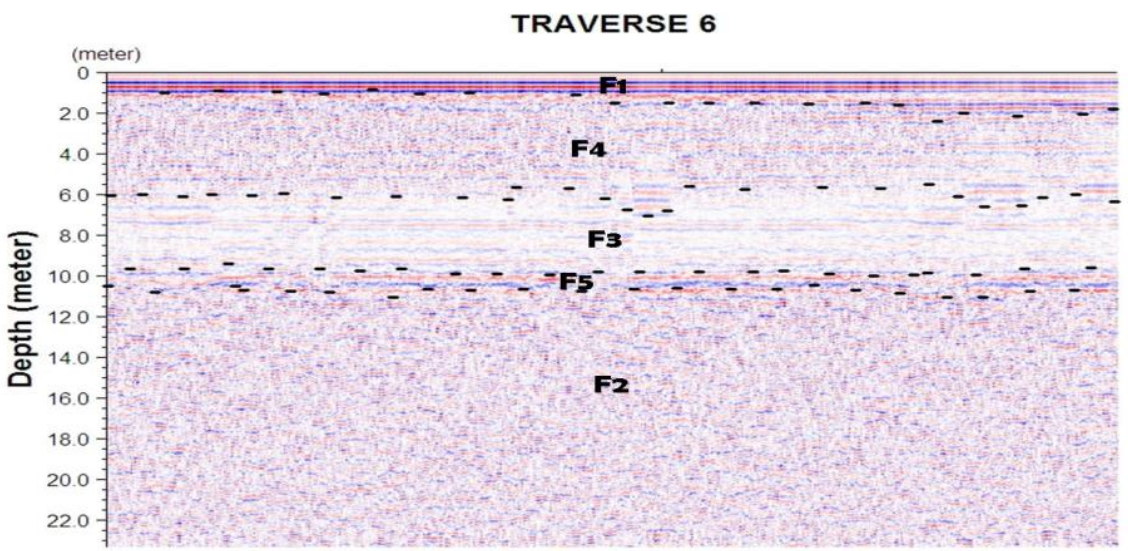

Fig. 10: Radar Facies for Traverse 6.

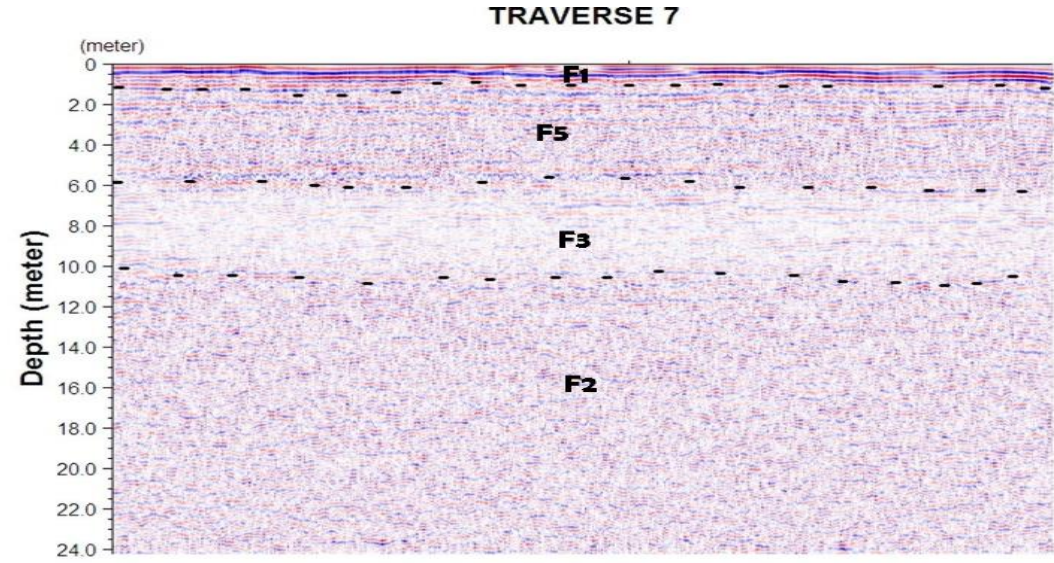

Fig. 11: Radar Facies for Traverse 7.

The GPR stratigraphy obtained at chainage point Ch.750m (Figure 13) reveals relatively thin parallel to sub-parallel, horizontal reflections with good continuity which is interpreted as top soil/sand-filled layer; the study area is marshy and so various portions have been sand-filled to enable accessibility. The water table exists just beneath this layer. The topsoil is absent on the portion of the traverse run on water and is replaced by the refuse- and litter-ridden water column. The topsoil is underlain by a layer with high amplitude, sinuous, horizontal, chaotic, moderately continuous reflections. This layer interpreted as silty-sand has thickness varying from 0.8 to $4.5 \mathrm{~m}$. Low amplitude (almost reflection-free) planar, moderately continuous reflections with a thickness of 3.5 to $7 \mathrm{~m}$ underlay the silty-sand unit. This is the layer of interest (peat) and the depth of occurrence ranges from $1.5 \mathrm{~m}$ to $9 \mathrm{~m}$ along the traverse. Moderate to high amplitude, planar, horizontal, subparallel reflections which became more prominent on approaching the river underlay the peat layer. This sandy/clayey layer had a marked boundary with the overlying peat, although the radar im- age showed a gradual transition between these sandy/clayey layers. A thick sequence of discontinuous chaotic reflections with high amplitude and sinuous configuration interpreted as silty-sand underlie the sandy/clayey unit.

The GPR stratigraphy obtained at chainage point Ch. 900m (Figure 14) showed similarity to $\mathrm{Ch} .1000 \mathrm{~m}$. The geometry of the river bed was clearly shown on the GPR section and the river base had a maximum depth of $3.5 \mathrm{~m}$. Domestic waste such as refuse, sewage and plants were seen on the river and such materials were held in suspension in the water. Furthermore, part of these had settled to the base as undecomposed peat/clay and waste with thickness range of 1 to $2 \mathrm{~m}$. This layer directly overlay the peat which has similar geometry with that seen along Ch.750m. The clayey-sand layer beneath the peat unit had straddled in it, sandy clay units in places, showing a gradual change in thickness and geometry of the clayey/sandy layer from land to water. The shallow-occurring silty-clay unit on land was seen to occur much deeper at $10 \mathrm{~m}$ (Figure 14). 
The GPR stratigraphy obtained at chainage point Ch.1000mshowed similarity to $\mathrm{Ch} .900 \mathrm{~m}$, but for the presence of sedimentary structures (ripples marks) within the peat (Figure 15), which is indicators of the transportation medium and paleo-current direction of the peat. As indicated by the ripple marks, the peat was possibly deposited in fluvial environment with the N-S direction of flow.

\section{TRAVERSE 8}

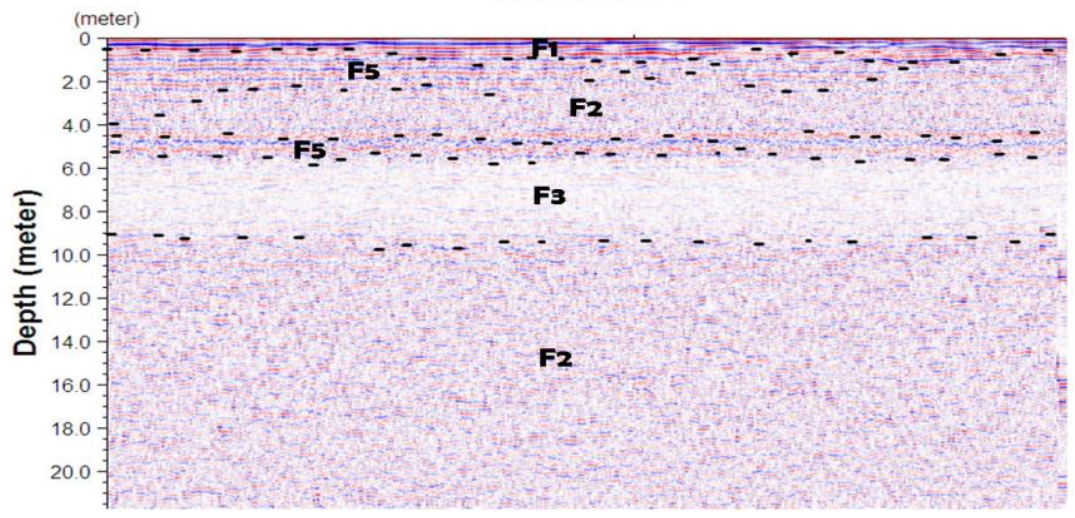

Fig. 12: Radar facies for Traverse 8

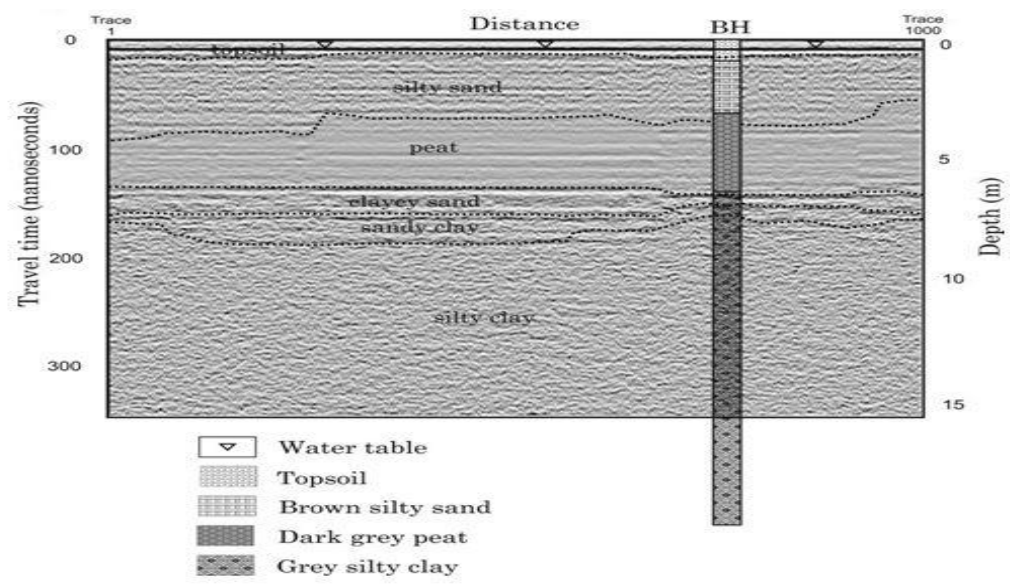

Fig. 13: GPR Reflection at Ch.750m (North - South Direction).

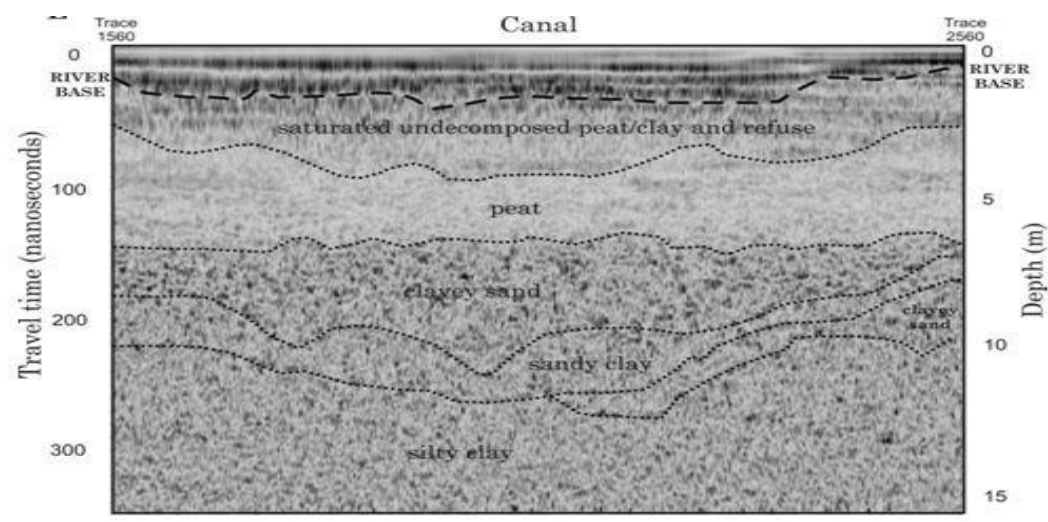

Fig. 14: GPR Reflection at Ch.900m (North - South Direction).

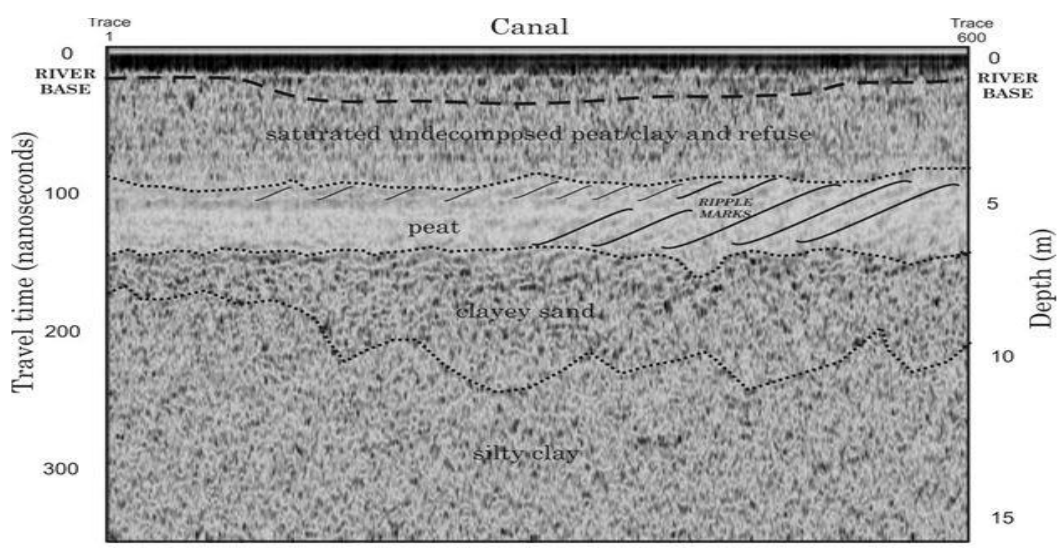

Fig. 15: GPR Reflection at Ch.1000m (North - South Direction). 


\subsection{Correlation and $3 D$ interpretation}

The boreholes logs obtained in the study area were correlated across four of the GPR traverses (Figure 16). Also, 3D cubes which show the spatial and lateral extent of the peat layer were produced from the combination of the 2D GPR sections obtained in the study area. This is presented in Figures16 to 19.

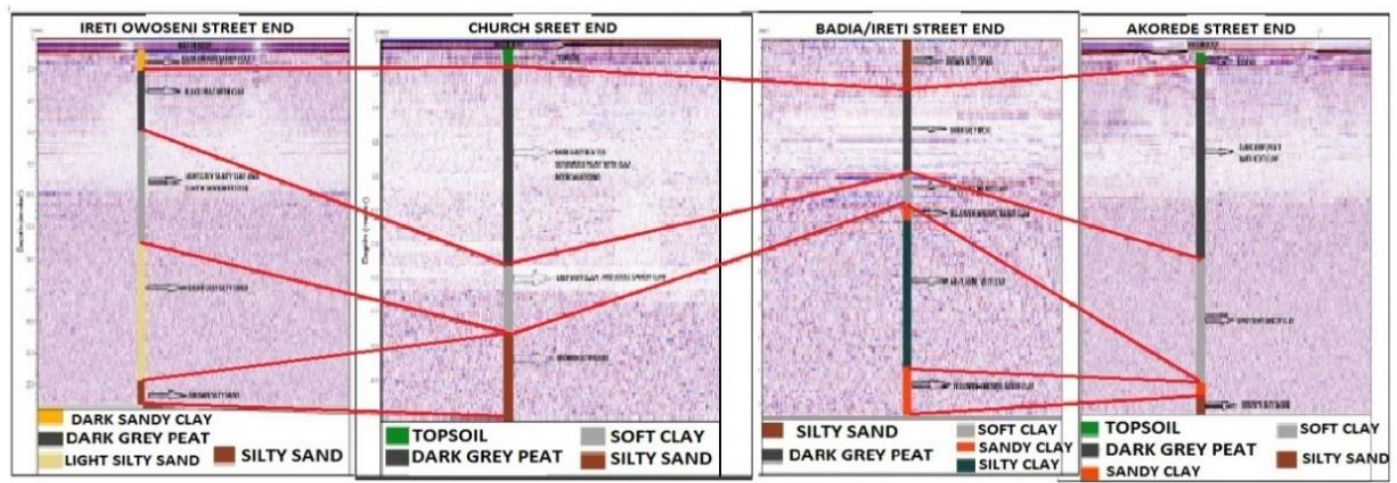

Fig. 16: Correlation of the Four Borehole Logs with the GPR Facies.

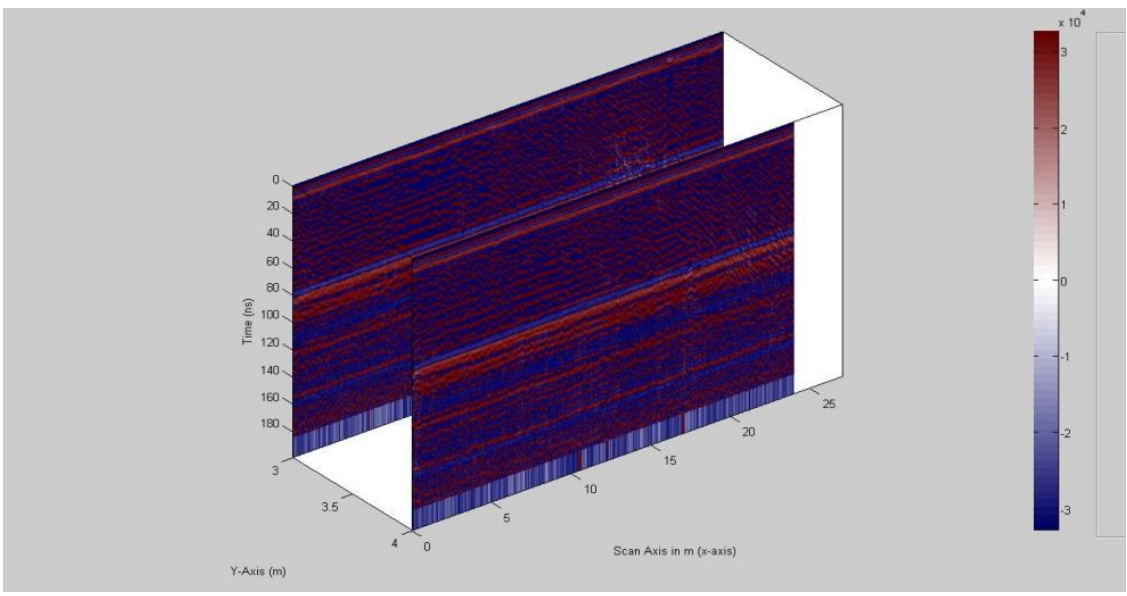

Fig. 17: Representative 3D Section of Traverse.

\subsection{Bathymetric measurement results}

The results of the depth to the water-Bed measurements taken on the field are shown as two-dimensional (2D) and threedimensional (3D) plots. Assuming the water level on land is at 0 datum, while the top to the depth of the canal floor from about ( $275 \mathrm{~m}$ - (end of traverse) ranges from ( $0 \mathrm{~m}$ - to $2 \mathrm{~m}$ ).

\subsection{Engineering parameters derived from GPR}

An attempt was made to calculate the intrinsic elastic and engineering properties of the peat unit from the geometry and thick- ness of the peat layer(s) observed on the GPR sections with the use of empirical equations.

The empirical equations given by Hamilton (1971), Lal (1991), Topp (1980), and Olhoeft (1979) were employed to derive the engineering parameters such as the bedding stress (deviatoric stress), porosity, density, Poisson ratio, elastic moduli etc. of the peat unit. The explanation keys for the equation $1-13$ used in this study are shown in Appendix B. The values of the engineering parameters obtained are shown in Table 2 respectively.

The derived engineering parameters from the GPR studies suggest that the Peat found in the investigated area at Badia are fibrous peat with low strength, medium to low bedding stress and high water volume content.

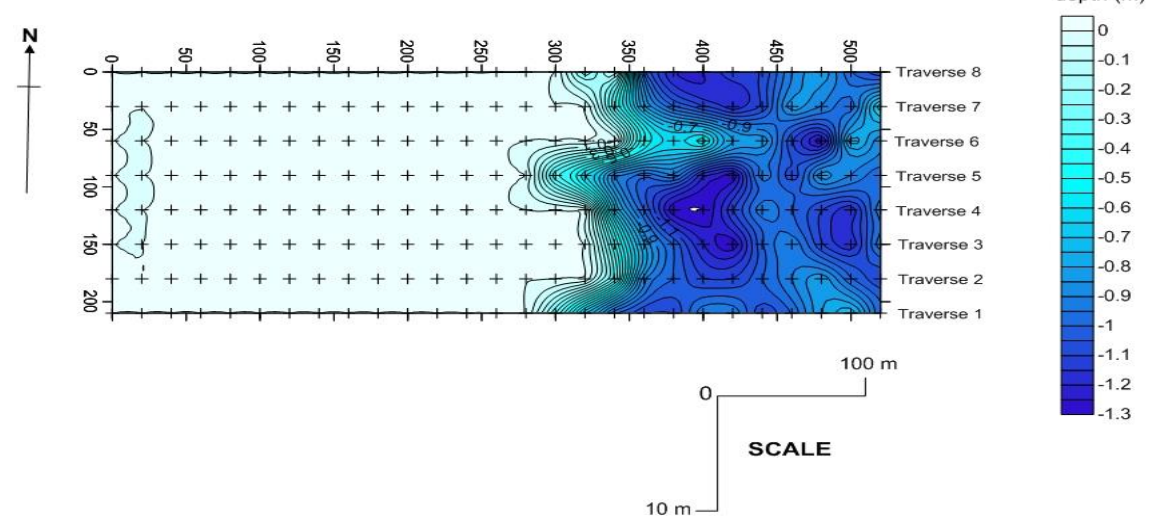

Fig. 18: 2D Representation of the Depth to Water Table in the Study Area. 


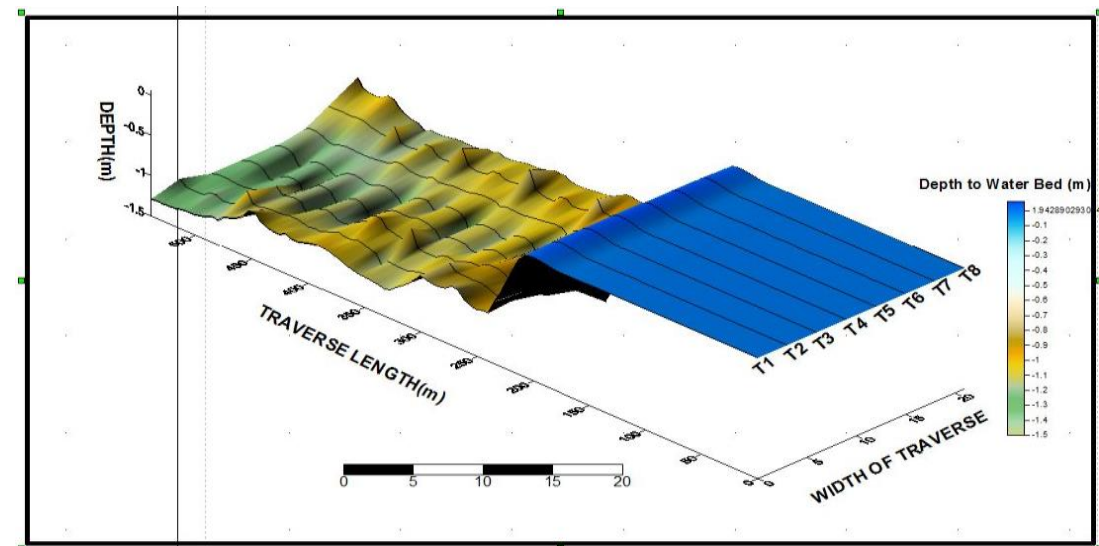

Fig. 19: $3 d$ Representation of the Depth to Water Table in the Study Area.

Table 2: Engineering and Elastic Parameters Derived from GPR Data

\begin{tabular}{|c|c|c|c|c|c|c|c|c|c|c|c|}
\hline $\begin{array}{l}\text { DEPT } \\
\mathrm{H}(\mathrm{m})\end{array}$ & $\begin{array}{l}\text { POROS- } \\
\text { ITY }(\varnothing)\end{array}$ & $\begin{array}{l}\mathrm{Vp} \\
(\mathrm{km} / \mathrm{s} \\
)\end{array}$ & $\begin{array}{l}\text { Vs } \\
(\mathrm{km} / \mathrm{s} \\
)\end{array}$ & $\begin{array}{l}\text { Density } \\
(\mathrm{g} / \mathrm{cc})\end{array}$ & $\begin{array}{l}\text { Poisson } \\
\text { ratio }(\mu)\end{array}$ & $\begin{array}{l}\text { Young modu- } \\
\text { lus }(\mathrm{GPa})\end{array}$ & $\begin{array}{l}\text { Shear modu- } \\
\text { lus (GPa) }\end{array}$ & $\begin{array}{l}\text { UCS } \\
(\mathrm{Mpa})\end{array}$ & $\begin{array}{l}\text { Internal } \\
\text { friction }(\theta)\end{array}$ & $\begin{array}{l}\text { Bulk } \\
\text { Modulus }\end{array}$ & $\begin{array}{l}\text { Bedding } \\
\text { Stress }(\mathrm{dP})\end{array}$ \\
\hline 1.5 & 0.33 & 1.83 & 0.88 & 2.02 & 0.35 & 4245.3523 & 1575.0289 & 7.1935 & 4.01 & $\begin{array}{l}4646.01 \\
09\end{array}$ & 4.88 \\
\hline 2 & 0.32 & 1.82 & 0.88 & 2.02 & 0.35 & 4208.2304 & 1261.2644 & 6.2953 & 4.01 & $\begin{array}{l}4605.18 \\
14\end{array}$ & 4.27 \\
\hline 3 & 0.35 & 1.84 & 0.89 & 2.03 & 0.35 & 4312.1256 & 1299.7876 & 9.3928 & 3.02 & $\begin{array}{l}4719.45 \\
56\end{array}$ & 6.37 \\
\hline 5 & 0.35 & 1.85 & 0.89 & 2.03 & 0.35 & 4369.9804 & 1321.2395 & $\begin{array}{l}12.264 \\
6\end{array}$ & 3.91 & $\begin{array}{l}4783.09 \\
34\end{array}$ & 8.31 \\
\hline 6 & 0.33 & 1.84 & 0.89 & 2.03 & 0.35 & 4342.0939 & 1210.8995 & $\begin{array}{l}10.733 \\
1\end{array}$ & 5.03 & $\begin{array}{l}4752.41 \\
91\end{array}$ & 7.28 \\
\hline 7 & 0.33 & 1.83 & 0.89 & 2.02 & 0.35 & 4279.9298 & 1387.8498 & 8.2199 & 5.00 & $\begin{array}{l}4684.04 \\
26\end{array}$ & 5.57 \\
\hline 8 & 0.32 & 1.84 & 0.89 & 2.03 & 0.35 & 4312.1256 & 1399.7876 & 9.3928 & 5.01 & $\begin{array}{l}4719.45 \\
56\end{array}$ & 6.37 \\
\hline 9 & 0.34 & 1.86 & 0.89 & 2.03 & 0.36 & 4208.2304 & 1293.7719 & 7.1935 & 6.32 & $\begin{array}{l}4646.01 \\
09\end{array}$ & 4.27 \\
\hline 10 & 0.35 & 1.87 & 0.88 & 2.02 & 0.36 & 4312.1256 & 1375.0289 & $\begin{array}{l}10.264 \\
1\end{array}$ & 6.30 & $\begin{array}{l}4783.09 \\
34\end{array}$ & 6.37 \\
\hline 11 & 0.35 & 1.86 & 0.88 & 2.03 & 0.34 & 4245.3523 & 1321.2395 & 8.6314 & 6.01 & $\begin{array}{l}4752.41 \\
91\end{array}$ & 6.88 \\
\hline 12 & 0.34 & 1.84 & 0.88 & 2.03 & 0.34 & 4369.9804 & 1204.8005 & 8.1099 & 3.05 & $\begin{array}{l}4684.04 \\
26\end{array}$ & 8.31 \\
\hline 13 & 0.35 & 1.85 & 0.89 & 2.02 & 0.35 & 4208.2304 & 1212.8498 & 7.3785 & 8.02 & $\begin{array}{l}4719.45 \\
56\end{array}$ & 6.28 \\
\hline 14 & 0.34 & 1.87 & 0.88 & 2.03 & 0.35 & 43654.9104 & 1610.8995 & 7.1935 & 4.35 & $\begin{array}{l}4646.01 \\
09\end{array}$ & 6.57 \\
\hline 15 & 0.35 & 1.88 & 0.89 & 2.04 & 0.35 & 4342.0939 & 1587.8498 & $\begin{array}{l}11.204 \\
1\end{array}$ & 4.38 & $\begin{array}{l}4783.09 \\
34\end{array}$ & 6.37 \\
\hline 16 & 0.32 & 1.84 & 0.89 & 2.04 & 0.35 & 4271.9168 & 1578.7171 & 8.7001 & 10.01 & $\begin{array}{l}4746.01 \\
09\end{array}$ & 7.27 \\
\hline 17 & 0.31 & 1.88 & 0.89 & 2.04 & 0.35 & 4356.1206 & 1594.6090 & 9.2009 & 10.00 & $\begin{array}{l}4605.18 \\
14\end{array}$ & 8.31 \\
\hline
\end{tabular}

\section{Conclusions}

The GPR data acquired in the study area revealed the presence of five distinct radar facies namely; topsoil, silty clay, peat, sandy clay and silty sand. The stratigraphic unit of interest, peat, was correlated across the eight GPR traverses studied and revealed the peat layer has varying thickness from $3 \mathrm{~m}$ to $11 \mathrm{~m}$ in the subsurface. The depth of occurrence of the peat also ranged from $1.5 \mathrm{~m}$ to $6 \mathrm{~m}$.An obvious decrease in depth to the peat vis-à-vis peat thicknesses from Ch.625 m to Ch.1100 m was obtained.

In addition, correlation of the results of the GPR data with the borehole log suites obtained in the area showed marked similarities in depth and thickness of the peat bogs. Furthermore, an attempt was made to infer the in-situ engineering and elastic properties of the peat from the GPR data. The derived engineering parameters from the GPR studies shows that the Peat found in the investigated area at Badia are fibrous peat with low strength, medium to low bedding stress and high volumetric water content (VWC).

High resolution Ground Penetrating Radar and hydrographic survey have revealed the general geometry and architecture, sedimentary units and patterns existing in the Badia Canal area of Lagos. Good correlation exists between the engineering properties estimated from the GPR data and the field data obtained.

\section{References}

[1] Adegoke, O. S., Jeje, L. K., Durotoye, B., Adeleye, and Ebukanson, E, E (1980). The Geomorphology and aspects of sedimentology of coastal region of Western Nigeria. Journal of Mining and Geology, 17 , pp. 217-223.

[2] Adepelumi, A. A., and Olorunfemi, M. O. (2000): Engineering geological and geophysical investigation of the reclaimed Lekki Penin- 
sula, Lagos, Southwest Nigeria., Bulletin of Engineering Geology $\begin{array}{llll}\text { and the } & \text { Environment, } 58 & \text { (2), } 125-132\end{array}$ https://doi.org/10.1007/s100640050006.

[3] Annan, A. P. (1992): Ground Penetrating Radar Workshop Notes. Sensors and Software Inc., Mississauga, Ontario, 56 pp.

[4] Annan, A. P. (2002): The history of ground penetrating radar. Subsurface Sensing Technologies and Applications, 3, 303 - 320. https://doi.org/10.1023/A:1020657129590.

[5] Apapa Local Government (2002): Planning Information on Badia: A blighted Area.

[6] Bjelm, M. (1980): Geological Interpretation with subsurface radar in peat lands. In Proceedings 6th International Peat Congress, Duluth, Minnesota; 7-8.

[7] Cassidy, N. J. (2009): Ground Penetrating Radar data Processing, Modelling and Analysis. In: https://doi.org/10.1016/b978-0-44453348-7.00005-3.

[8] Comas, X., Slater, L., Reeve, A. (2004): Geophysical evidence for peat basin morphology and stratigraphic control on vegetation observed in Northern Peat land. Journal of Hydrology295: 173-184. https://doi.org/10.1016/j.jhydrol.2004.03.008

[9] Comas, X., Slater, L., Reeve, A. (2005): Stratigraphic controls on pool formation in a domed bog inferred from ground penetrating radar GPR. Journal of Hydrology315: 40-51. https://doi.org/10.1016/j.jhydrol.2005.04.020.

[10] Davis, J. L., Annan, A. P. (1989): Ground-penetrating radar for high resolution mapping of soil and rock stratigraphy. Geophys.Prospect. 3, 531 - 551. https://doi.org/10.1111/j.13652478.1989.tb02221.x.

[11] Durotoye, A. B. (1975): Quaternary sediments in Nigeria (C.A. Kogbe edited). Geology of Nigeria, Elisabeth Press, Lagos, pp.431451.

[12] Fisher, E., McMechan, G. A., Annan, A. P., Cosway, S. W. (1992): Acquisition and processing of wide-aperture ground-penetrating radar data. Geophysics 57, 495 - 504 https://doi.org/10.1190/1.1443265.

[13] Hanninen, P. (1992): Application of ground penetrating radar techniques to peatland investigations. 4th International Conference on GPR, Rovaniemi, Finland 1992. Geological Survey of Finland, Special Paper 16; 217-221.

[14] Hill, M. B and J. E. Webb, J. E (1958): The Ecology of Lagos Lagoon. II. The Topography and Physical Features of Lagos Harbour and Lagos Lagoon. Phil. Trans. R. Soc. Lond. B 4 September 1958 vol. 241 no. 683 319-333. https://doi.org/10.1098/rstb.1958.0006.

[15] Huat, B. K., Asadi, A and Kazemian, S. (2009): Experimental in vestigation of Geomechanical properties of Tropical Organic Soils and Peat. American Journal of Engineering and Applied Sciences2 (1): 184-188. https://doi.org/10.3844/ajeassp.2009.184.188.

[16] Iloeje, N.P (1976): A new geography of Nigeria. Longmans Publishers, London, $34 \mathrm{p}$.

[17] Integrated Geosciences Services (2013)

[18] Jones, H.A and Hockey, R. D (1964): The Geology of part of Southwestern Nigeria, Geological Survey of Nigeria, Bulletin 31, pp. 10-34.

[19] Longe, E.O., Malomo, S., and Olorunniwo, M.A., (1987). Hydrogeology of Lagos metropolis, Journal of African Earth Sciences, 6, 3, 163-174. https://doi.org/10.1016/0899-5362(87)90058-3.

[20] Mitchum, R. M.., Vail, P. R., and Sangree, J. B. (1977). Stratigraphic interpretation of seismic reflection patterns in depositional sequences. In: Payton, C. E. (Ed), Seismic StratigraphyApplications to Hydrocarbon Exploration. AAPG Mem. 16, 117 123.

[21] Neal, A. (2004): Ground-penetrating radar and its use in sedimentology: principles, problems, and progress. Earth Science Review, 66, 261-330. https://doi.org/10.1016/j.earscirev.2004.01.004.

[22] Olhoeft, G.R. (1988): Interpretation of Hole-to-Hole Radar Measurements. Proceedings of the Third Technical Symposium

[23] Olsson, O., Anderson, P., Carlsten, S., Falk, L., Niva, D., Sandberg, E. (1992): Fracture Characterization in Crystalline Rock by Borehole Radar, Ground Penetrating Radar. Geological Survey of Canada, Paper 90-4, pp. 139 - 150. https://doi.org/10.4095/133657.

[24] Olsson, O., Falk, L., Forslund, O., Sandberg, E. (1987): Crosshole Investigations - Results from Borehole Radar Investigations. Stripa Project TR 87 - 11. SKB, Stockholm, Sweden.

[25] Omatsola, M. E. and Adegoke, O. S. (1981): Tectonic evolution and Cretaceous Stratigraphy of Dahomey basin. Journal of Mining and Geology, 18 (1); 130-137

[26] Warner, B. G., Nobes, D., Theimer, B. D. (1990): An application of ground penetrating radar to peat stratigraphy of Ellice Swamp, southwestern Ontario. Canadian Journal of Earth Sciences27; 932938. https://doi.org/10.1139/e90-096.
[27] Worsfold, R. D., Parashar, S. K., Perrott, and T. (1986): Depth profiling of peat deposits with impulse radar. Canadian Geotechnical Journal23; 142-186. https://doi.org/10.1139/t86-024. 